\title{
Saberes ambientais dos alunos dos cursos técnicos de nível médio da Escola Técnica de Saúde da Universidade Federal da Paraíba
}

\section{Karine da Silva ${ }^{1}$, Francisco José Pegado Abílio ${ }^{2}$ e Theóffillo da Silva Lopes ${ }^{3}$}

\author{
${ }^{1}$ Universidade Federal da Paraíba. Centro de Educação. Curso de Graduação em \\ Pedagogia. Campus I. Cidade Universitária. João Pessoa-PB, Brasil \\ (CEP 58051-900). \\ ${ }^{2}$ Universidade Federal da Paraíba. Centro de Educação. Departamento de \\ Metodologia da Educação. Campus I. Cidade Universitária. João Pessoa-PB, Brasil \\ (CEP 58051-900). \\ ${ }^{3}$ Universidade Federal da Paraíba. Centro de Educação. Programa de \\ Pós-Graduação em Educação. Campus I. Cidade Universitária. João Pessoa-PB, \\ Brasil (CEP 58051-900). E-mail: theoffillo@outlook.com.
}

Resumo. 0 crescimento industrial desenfreado da globalização e a as diversas ações proporcionadas pelo homem remetem a discussões na educação, em todos os níveis de ensino, sobre a crise ambiental. Diante disso, essa pesquisa buscou investigar os saberes ambientais dos alunos dos cursos técnicos da Escola Técnica de Saúde da UFPB antes e após a aplicação de um curso de extensão. Para isso, foi utilizada uma pesquisa-ação de caráter qualitativo durante a aplicação do curso e houve a aplicação de dois questionários, um ao início e outro ao final do curso. Como resultado, obtivemos o desenvolvimento de uma maior criticidade dos alunos e uma quebra de pensamentos reducionistas acerca das questões ambientais que envolvem suas práxis.

Palavras-chave: Educação ambiental; Meio ambiente; Saberes ambientais.

Abstract. The environmental knowledge of students of the middle-level technical courses at Thecnical School of Health at Federal University of Paraíba. The industrial growth developed by globalization and how various actions provided by man leads to discussions in education, at all levels of education, about an environmental crisis. Therefore, this research sought to investigate the environmental knowledge of students in technical courses at the Technical School of Health at UFPB before and after applying an extension course. A qualitative action research was used during the course application and two questionnaires were applied, one at the beginning and one at the end of the course. As a result, obtain or develop greater criticism from students and a
Recebido

$06 / 06 / 2021$

Aceito

09/07/2021

Disponível on line

$11 / 07 / 2021$

Publicado

$31 / 08 / 2021$

Acesso aberto

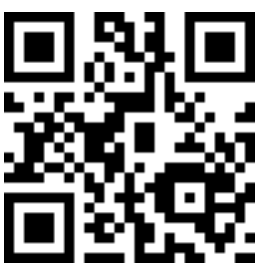

D) $0000-0001-6000-6277$ Karine da Silva

(D) 0000-0002-7217-4849 Francisco José Pegado Abílio 
breakdown of reductionist thoughts on environmental issues surrounding their praxis.

Keywords: Environmental education; Environment; Environmental knowledge.
0000-0002-7775-4885

Theóffillo da Silva

Lopes

\section{Introdução}

Problematizar e refletir sobre a crise ambiental enfrentada pela humanidade, significa reconhecer a importância da busca por meios e posturas que revertam ou amenizem os danos exercidos de modo avassalador ao meio em que vivemos.

Com a Revolução Industrial, gradativamente o trabalho artesanal foi sendo trocado pela mão de obra assalariada. Hobsbawm (2014) afirma que há a vertente de que a fábrica precisa de recursos naturais para manter o seu funcionamento, e aí iniciou a problemática do uso desenfreado desses recursos por parte de muitos, além do despejamento de materiais nocivos à saúde humana na natureza. Toda essa industrialização domou a Europa para finalmente chegar ao Brasil e explicar a crise ambiental.

A problemática surgida com isso e após toda a essa industrialização é a do consumo inconsciente e alienado, sem avaliar o impacto social e ambiental que tal atitude é capaz de remeter. A produção do capitalismo gera consumos ilimitados, os mesmos são produzidos através de poluição ilimitadas que são superiores a capacidade do planeta, o mundo passou a se resumir na busca pelo lucro e não pela satisfação de necessidades.

Nesse âmbito de desigualdades, houve uma inquietação para abordar se a educação ambiental vem sendo remetida de forma reflexiva no ensino técnico de nível médio da Escola Técnica de Saúde, da Universidade Federal da Paraíba (ETS/UFPB), uma vez que o estágio na Escola Técnica de Saúde proporcionou abertura e facilidade ao desenvolvimento do trabalho de investigação, já que existiu a anuência da direção e dos colegiados dos cursos da escola.

A educação profissional técnica de nível médio proporciona, em curto prazo, uma formação para que os alunos possam ingressar no mercado de trabalho de uma maneira mais rápida. De acordo com a Resolução MEC/CNE/CEB no 06/2012, do Conselho Nacional de Educação (Brasil, 2012) é obrigatória a presença de gestão ambiental e gestão de qualidade social e ambiental do trabalho na organização curricular dos cursos técnicos.

Compreende-se, portanto, a necessidade da identificação dos saberes ambientais dos alunos dos cursos técnicos de nível médio da ETS/UFPB, através do curso de extensão "Meio Ambiente e Ação Humana: uma perspectiva educacional na formação do técnico", no qual houve a participação da autora deste trabalho como aplicadora voluntária.

Desse modo, a participação como aplicadora do curso de extensão trouxe subsídios metodológicos que caracterizam este trabalho como uma pesquisa-ação, na qual a partir de análises participantes sobre os conhecimentos anteriores e posteriores dos alunos do curso, pudemos apresentar algumas possibilidades de construção de valores para a formação de agentes sociais transformadores.

Nesse sentido, o presente trabalho teve como objetivo geral investigar a evolução dos saberes ambientais dos alunos dos cursos técnicos de nível médio da ETS/UFPB antes e após curso de extensão. Bem como teve os seguintes objetivos específicos (a) identificar os saberes ambientais dos alunos dos cursos técnicos de nível médio da ETS/UFPB; e (b) analisar quais as modificações de concepções que os alunos sofreram no conhecimento prévio e após o curso de extensão. 


\section{Meio ambiente e educação ambiental}

Em primeira instância, para que haja compreensão da crise ambiental e das consequências que ela remete em aspectos sociais, culturais, econômicos, ecológicos e naturais é necessário o entendimento acerca do conceito de meio ambiente e a importância de que no sistema educacional estabeleça presença de uma educação ambiental crítica.

Diante de todos os estudos realizados e dados identificados por Camozzato (2012), em 1972 houve uma Conferência das Nações Unidas pautada no Meio Ambiente realizada em Estocolmo, Suécia, com representantes de 113 países que o conceituou como: "O meio ambiente é o conjunto de componentes físicos, químicos, biológicos e sociais capazes de causar efeitos diretos ou indiretos, em um prazo curto ou longo, sobre os seres vivos e as atividades humanas". Essa mesma Conferência deu origem a Declaração de Estocolmo que afirmou o direito das gerações futuras de viverem em um ambiente que garanta saúde e sem degradações.

Ainda de acordo com Camozzato (2012) a Conferência de Estocolmo foi uma das principais, mas também houve algumas outras de semelhante importância, como a Eco-92 que teve um grande amparo da mídia resultando na assinatura de grandes acordos ambientais na representação de 172 países ou a Rio+10, em 2002, realizada em Johanesburgo, na África do Sul, que sinalizou uma grande crítica aos países mais desenvolvidos por não tentarem o combate às desigualdades sociais.

Outro conceito de meio ambiente cabível de uma boa analise é o lançado pela Política Nacional do Meio Ambiente (PNMA), pela Lei no 6.938/1981, que conceitua o meio ambiente como "o conjunto de condições, leis, influências e interações de ordem física, química e biológica, que permite, abriga e rege a vida em todas as suas formas" (Brasil, 1981). Tendo a PNMA o objetivo de regulamentar atividades que envolvam o meio ambiente, sua preservação e qualidade.

Enrique Leff, um dos mais reconhecidos intelectuais da temática ambiental em perspectivas transdisciplinares define o meio ambiente como:

O ambiente não é o meio que circunda as espécies e as populações biológicas; é uma categoria sociológica (e não biológica), relativa a uma racionalidade social, configurada por comportamentos, valores e saberes, bem como por novos potenciais produtivos (Leff, 2007, p. 160).

Neste sentido, o ambiente do sistema econômico está constituído pelas condições ecológicas de produtividade e regeneração dos recursos naturais, bem como pelas leis termodinâmicas de degradação de matéria e energia no processo produtivo. 0 ambiente estabelece potenciais e limites às formas e ritmos de exploração dos recursos, condicionando os processos de valorização, acumulação e reprodução do capital.

Evidencia-se que a educação ambiental aplicada de forma adequada cria meios para que haja consciência dos reflexos da produção e do consumo excessivo, pois, "ensinar não é transferir conhecimento, mas criar as possibilidades para a sua produção ou a sua construção" (Freire, 1996, p. 22).

A educação é entendida por Althusser (1977) como um aparelho ideológico de Estado, contudo, é a educação que produz vozes de resistência. Neste sentido, a própria subjetividade encarada enquanto instrumento de controle, também pode atuar como fomento de justiça social.

A educação é, neste aspecto, ferramenta imprescindível no processo de transformação social, porém o seu discurso deve superar a as ideias reducionistas sobre meio ambiente. No entanto, a internalização das condições da racionalidade ambiental é um processo lento e multifacetado, por que é dotado de uma inversão do pensamento da cultura humana. 


\section{Educação ambiental crítica}

A educação ambiental por si é um caminho complexo que exige que os participantes da mesma problematizem, reflitam e pensem sobre o meio ambiente com criticidade. Na verdade, a maioria dos conceitos sobre educação ambiental são extremamente reducionistas e naturalistas, ou seja, conceitos reduzidos às dimensões físicas e biológicas da natureza.

De acordo com Loureiro (2008), a concepção conservadora de educação ambiental se interessa pela conservação das estruturas sociais, econômicas, políticas, éticas e culturais. Esta caracteriza-se por: uma visão reducionista da questão ambiental; compreensão naturalista e conservacionista da crise ambiental; sobrevalorização das respostas tecnológicas; leitura individualista dos problemas ambientais; abordagem despolitizada; perspectiva crítica e interdisciplinar limitada ou inexistente; separação entre as dimensões sociais e naturais; responsabilização dos impactos ambientais destinado ao homem genérico, descontextualizado econômica e politicamente.

Ainda de acordo com Loureiro (2008), uma educação ambiental crítica e emancipatória destina-se para que as pessoas portem a consciência de que fazem parte do meio e que protegê-lo é o mesmo que proteger a humanidade, esse pensamento precisa ser desenvolvido nos jovens de forma efetiva.

Ao abordarmos Loureiro (2008), identificam-se duas perspectivas da educação ambiental com construções diferentes. 0 eixo emancipatório, que se baseia em Paulo Freire, Morin, Leff, que defendem a educação crítica, composta de práticas e com um poder de transformar o indivíduo, moldá-lo para enfrentar as realidades ambientais com temas geradores, ou seja, de forma significativa, da melhor maneira que o seu eu consiga refletir. 0 eixo reducionista oferece privilégio para um pensamento de ações pontuadas, sem necessariamente ter ligações com o pensamento reflexivo como na abordagem anterior, a visão é sempre conservadora.

Sendo a educação ambiental um meio de transformação com a qual se pode buscar soluções ou melhorias para a situação emergente que o mundo se encontra. É necessário que haja educadores que atuem sob a perspectiva da educação ambiental crítica e de um sistema de ensino que englobe a educação ambiental desde muito cedo, de forma transdisciplinar.

A educação neste contexto possui um papel holístico de formar pessoas transformadoras de uma crise advinda de fatos históricos, a superação do reducionismo é uma peça chave nessa transformação.

\section{A importância da educação ambiental para o ensino técnico de nível médio}

Para entender a importância da educação ambiental para o ensino técnico de nível médio é necessário que saibamos que esse tipo de formação se define como uma combinação de conhecimentos teóricos e práticos, relacionados a uma área específica para alunos matriculados ou egressos do ensino médio. 0 propósito é a habilitação técnica após a conclusão. Caracteriza-se por ser um meio rápido de ingresso no mercado de trabalho e isso pode acarretar uma alta demanda de procura por esse tipo de formação.

Como mencionamos anteriormente, a Educação Ambiental é fundamental no sistema educacional como um todo para conscientizar e formar atores transformadores para a grave crise ambiental que temos enfrentado, no século XXI.

No ensino técnico de nível médio essa situação não é diferente, a educação nesta etapa da formação humana tem responsabilidade na construção e na ressignificação de conceitos adquiridos pela sociedade no decorrer da História, que podem ter resultados extremamente satisfatórios em termos de transformação social a partir desses profissionais. 
A prática da educação ambiental incentiva, um uso consciente de recursos naturais e a prática de ações ecologicamente corretas em todos os ambientes, ou seja, o desenvolvimento humano de uma forma que preserve o ambiente em que todos estão inseridos. 0 profissional técnico que teve a oportunidade de presenciar a educação ambiental na sua formação remete a um profissional que sabe como ter atitudes reflexivas e críticas para assim poder tomar as melhores iniciativas em seu meio de vida e de trabalho.

O profissional técnico está inserido, na maioria das vezes, em locais de trabalhos que auxiliam ao crescimento da globalização, consumo e a presença de resíduos industriais que sobre passam a capacidade que o planeta tem de se regenerar, sem dúvidas esse profissional precisa estar preparado para ajudar a ter soluções que garantam a possível qualidade de vida de gerações futuras.

As Diretrizes Curriculares Nacionais para a Educação Ambiental (DCNEA), estabelecidas pela Resolução MEC/CNE/CP no 2, 2012 (Brasil, 2012), determinam que:

Art. 8. A Educação Ambiental, respeitando a autonomia da dinâmica escolar e acadêmica, deve ser desenvolvida como uma prática educativa integrada e interdisciplinar, contínua e permanente em todas as fases, etapas, níveis e modalidades, não devendo, como regra, ser implantada como disciplina ou componente curricular específico (Brasil, 2012).

É de extrema importância que na formação do ensino técnico haja educação ambiental para formar cidadãos críticos, reflexivos e possíveis transformadores de um sistema de destruição ambiental. Frisando sempre o papel que educador desse futuro profissional também tem, que é o de provocar estimulo para a concretização disso tudo, estudos e a reflexões para que em seu ambiente de trabalho esse profissional saiba como se portar.

Portanto, o que se espera quando a educação ambiental é colocada no ensino técnico de nível médio é que os indivíduos sejam capazes de argumentar conscientemente no cenário sociopolítico, uma vez que as mudanças ambientais não remetem apenas a presença da conscientização das pessoas, e pelo avanço de tecnologias facilitadoras, mas também um condicionamento de dimensões políticas, em coletividade.

\section{Aspectos metodológicos da pesquisa}

Esta pesquisa foi desenvolvida a partir da análise, investigação e compreensão dos saberes ambientais dos alunos dos cursos técnicos de nível médio da ETS/UFPB, antes e após aplicação de um curso de extensão intitulado "Meio Ambiente e Ação Humana: uma perspectiva educacional na formação do técnico", que foi realizado na ETS/UFPB.

Diante disso, optamos por realizar uma pesquisa-ação participante de caráter qualitativo. Segundo Godoy (1995) a abordagem qualitativa de pesquisa,

Envolve a obtenção de dados descritivos sobre pessoas, lugares e processos interativos pelo contato direto do pesquisador com a situação estudada, procurando compreender os fenômenos segundo a perspectiva dos sujeitos, ou seja, dos participantes da situação em estudo (Godoy, 1995, p. 58).

Sabendo que o objetivo geral da pesquisa foi analisar quais as modificações de concepções os alunos dos cursos técnicos de nível médio da ETS/UFPB sofreram no conhecimento prévio e após o curso de extensão, e que pesquisas do tipo qualitativas são realizadas quando o objetivo do estudo é entender o motivo de determinados comportamentos, individualidades, experiências particulares e outros aspectos pessoais, ou seja, a mesma é capaz de analisar dados que não são necessariamente mensurados 
numericamente, portanto, esse tipo de pesquisa é a que melhor se adequa ao tipo de fenômeno e objeto de estudo a se investigar.

Segundo Grossi (1981), uma das características da pesquisa participante é a participação da comunidade nas análises da problemática estudada e a busca por soluções para modificar a situação em benefício de um bem comum a todos.

Conforme Grossi (1981), a tensão existente entre o conhecimento e uso do conhecimento é um paradigma que a pesquisa participante desenvolve funções de resolver.

Thiollent (2011) afirma que, na maioria das pesquisas-ação, é necessário o uso de questionários e técnicas para um meio de informações complementares.

No decorrer do curso os alunos realizaram atividades nas quais puderam compartilhar as mudanças que as aulas acarretaram em seu cotidiano, houve uma atividade executada pelos alunos que foi posteriormente parâmetro para auxiliar a análise de dados, sendo essa uma das características atribuídas a pesquisa-ação. Os alunos também relatavam conforme as aulas passavam o quanto estavam aplicando os conhecimentos adquiridos nas aulas em seu dia a dia, muitas vezes até dentro da própria ETS/UFPB, corrigindo atitudes de terceiros e sendo agentes transformadores com suas pequenas atitudes.

Thiollent (2011) também define que nem toda pesquisa participante pode ser considerada uma pesquisa-ação, apesar de toda pesquisa-ação ser uma pesquisa participante. Isto é, quando uma pesquisa é participante há necessidade de analisar os problemas levando em conta situações específicas de cada caso.

Ainda de acordo com Thiollent (2011), a História da pesquisa participante surge em 1960, através do crescimento de camadas de grupos populares, marxistas e humanistas que se integraram em comunidades com o propósito de estudar o seu dia a dia e seus problemas.

Com isso, evidencia-se que, envolvendo sujeitos que possuíssem íntima relação com o objeto de estudo e atuassem diretamente na no cerne da questão a ser investigada, seria possível analisar com mais profundidade o tema, bem como propor soluções mais adequadas às problemáticas identificadas e estudadas.

Nesse sentido, acreditamos que essa investigação se enquadra nas definições de pesquisa-ação, pois se caracteriza por avaliar qualitativamente ao mesmo tempo em que promove uma interação entre pesquisadores e membros e há a exigência de ações de solução partindo do grupo ou participantes, exigência com a qual não existe quando a pesquisa é apenas de caráter participante.

\section{Metodologia}

Os seguintes passos foram executados até a conclusão da pesquisa: Inscrição de interessados no curso, via Sistema Integrado de Gestão de Atividades Acadêmicas, próprio da Universidade Federal da Paraíba, em um total de 40 vagas, aplicação do curso com um total de seis aulas ministradas com as temáticas: Meio ambiente e ser humano: da entropia a simbiose, Desequilíbrio ecológico e preservação ambiental, Meio ambiente, consumo e qualidade de vida, 0 ser humano e a educação na perspectiva ambiental, desenvolvimento e justiça ambiental, júri simulado sobre causa ambiental. Durante essas aulas foi aplicado um questionário na primeira aula e outro na última que possibilitaram a análise da evolução da compreensão dos alunos da ETS/UFPB sobre o saber ambiental. Durante essas aulas também foram aplicadas algumas outras atividades diversificadas que auxiliaram de forma positiva na análise de conteúdo, contando inclusive uma ação ambiental realizada pelos próprios alunos dentro da ETS/UFPB.

A análise de dados esteve amparada na perspectiva metodológica apresentada por Bardin (2011) sobre análise de conteúdo que se define por uma técnica de investigação

Rev. Bras. Gest. Amb. Sustent., 2021, vol. 8, n. 19, p. 847-861. 
que tem por finalidade a descrição objetiva, sistemática e quantitativa do conteúdo manifesto da comunicação. Com a ajuda das concorrências, toma-se consciência de que, a partir dos resultados da análise, se pode regressar às causas, ou até descer aos efeitos das características das comunicações. A intenção da análise de conteúdo é a inferência de conhecimentos relativos às condições de produção (ou, eventualmente, de recepção), inferência esta que recorre a indicadores (quantitativos ou não).

0 analista trabalha com índices cuidadosamente postos em evidência por procedimentos mais ou menos complexos. Se a descrição (a enumeração das características do texto, resumida após tratamento) é a primeira etapa necessária e se a interpretação (a significação concedida a estas características) é a última fase, a inferência (dedução de maneira lógica) é o procedimento intermediário, que vem permitir a passagem, explicita e controlada, de uma à outra (Bardin, 2011, p. 39).

A análise de conteúdos se resume em um conjunto de técnicas de análise das comunicações visando obter por procedimentos sistemáticos e objetivos de descrição do conteúdo das mensagens indicadores (quantitativos ou não) que permitam a inferência de conhecimentos relativos às condições de produção/recepção (variáveis inferidas) dessas mensagens. Por fim, a análise e interpretação dos dados à luz da fundamentação teórica.

\section{Resultados e discussão}

Diante da extensão aplicada na ETS/UFPB obtiveram-se os resultados através de uma estruturação de catalogação, codificação, inferência e interpretação dos dados, baseada no método de análise de conteúdo. Todo o desenvolvimento e trabalhos realizados são apresentados nas tabelas a seguir.

Tabela 1. Questão sobre meio ambiente e educação ambiental.

\begin{tabular}{|c|c|c|c|c|c|}
\hline Avaliação & $\begin{array}{l}\text { Unidades de } \\
\text { contextos }\end{array}$ & $\begin{array}{l}\text { Unidade de } \\
\text { registro }\end{array}$ & Frequência & Inferências & $\begin{array}{l}\text { Interpretações } \\
\text { prévias }\end{array}$ \\
\hline \multirow{19}{*}{ Prévia } & \multirow{19}{*}{ Reducionista } & Olhar & \multirow{19}{*}{$78 \%$} & \multirow{19}{*}{$\begin{array}{l}\text { Os discentes } \\
\text { apresentara } \\
\text { m noções de } \\
\text { que a } \\
\text { educação } \\
\text { ambiental e } \\
\text { o meio } \\
\text { ambiente } \\
\text { são coisas } \\
\text { atreladas a } \\
\text { preservação } \\
\text { da natureza, } \\
\text { mostraram } \\
\text { uma visão } \\
\text { desses } \\
\text { conceitos } \\
\text { como apenas } \\
\text { a um espaço } \\
\text { que } \\
\text { devemos } \\
\text { remeter } \\
\text { conservação. }\end{array}$} & \multirow{19}{*}{$\begin{array}{lr}\text { Na } & \text { trajetória } \\
\text { escolar } & \text { desses } \\
\text { discentes } & \text { é bem } \\
\text { provável } & \text { que a } \\
\text { formação } & \text { básica } \\
\text { sobre } & \text { meio } \\
\text { ambiente } & \text { e } \\
\text { educação } & \\
\text { ambiental } & \text { se } \\
\text { representou } & \text { de } \\
\text { uma maneira } \\
\text { insuficiente } \\
\text { necessidades } \\
\text { mundiais, } \\
\text { todos os aspectos } \\
\text { que o em } \\
\text { ambiental possui. }\end{array}$} \\
\hline & & Lugar & & & \\
\hline & & Aprender & & & \\
\hline & & Preservar & & & \\
\hline & & Valor & & & \\
\hline & & Ensinar & & & \\
\hline & & Viver & & & \\
\hline & & Lixo & & & \\
\hline & & Melhorar & & & \\
\hline & & Palestras & & & \\
\hline & & Educar & & & \\
\hline & & Natureza & & & \\
\hline & & Ecológico & & & \\
\hline & & Cuidar & & & \\
\hline & & Não poluir & & & \\
\hline & & Ecossistema & & & \\
\hline & & Espécies & & & \\
\hline & & Ciclo & & & \\
\hline & & $\begin{array}{l}\text { Saneamento } \\
\text { básico }\end{array}$ & & & \\
\hline
\end{tabular}


Tabela 1. Continuação.

\begin{tabular}{|c|c|c|c|c|c|}
\hline Avaliação & $\begin{array}{ll}\text { Unidades } \\
\text { contextos }\end{array}$ & $\begin{array}{l}\begin{array}{l}\text { Unidade } \\
\text { registro }\end{array} \\
\end{array}$ & Frequência & Inferências & $\begin{array}{l}\text { Interpretações } \\
\text { prévias }\end{array}$ \\
\hline \multirow[b]{14}{*}{ Somatória } & \multirow{13}{*}{$\begin{array}{l}\text { Complexo } \\
\text { Crítico } \\
\text { Reflexivo }\end{array}$} & Compreender & \multirow[t]{13}{*}{$22 \%$} & \multirow{13}{*}{$\begin{array}{l}\text { Alguns } \\
\text { discentes } \\
\text { obtiveram } \\
\text { contato com } \\
\text { o saber } \\
\text { ambiental } \\
\text { em uma } \\
\text { perspectiva } \\
\text { refletiva } \\
\text { durante a } \\
\text { sua } \\
\text { formação. }\end{array}$} & \multirow{13}{*}{$\begin{array}{l}\text { O investimento no } \\
\text { desenvolvimento } \\
\text { de um pensamento } \\
\text { crítico/reflexivo } \\
\text { em alguns } \\
\text { discentes teve } \\
\text { como } \\
\text { consequência } \\
\text { formação } \\
\text { respostas de mais } \\
\text { consistentes } \\
\text { melhor } \\
\text { relacionadas com o } \\
\text { saber ambiental. }\end{array}$} \\
\hline & & Discussão & & & \\
\hline & & $\begin{array}{l}\text { Melhorar o meio } \\
\text { ambiente }\end{array}$ & & & \\
\hline & & Aprofundamento & & & \\
\hline & & Conflitos & & & \\
\hline & & Responsabilidade & & & \\
\hline & & Conhecimento & & & \\
\hline & & Harmonia & & & \\
\hline & & $\begin{array}{ll}\text { Mudança } \\
\text { atitudes }\end{array}$ & & & \\
\hline & & $\begin{array}{l}\text { Pensamento } \\
\text { crítico }\end{array}$ & & & \\
\hline & & Mentalidade & & & \\
\hline & & Conscientizar & & & \\
\hline & & Refletir & & & \\
\hline & Reducionista & Aprendizado & $31 \%$ & $\begin{array}{ll}\text { Sendo } \quad o\end{array}$ & $\begin{array}{lll}0 & \text { processo } & \mathrm{de}\end{array}$ \\
\hline & & Disciplina & & saber & aprendizagem na \\
\hline & & Natureza & & ambiental & educação básica \\
\hline & & Educar & & extremamen & não teve suporte \\
\hline & & Biodiversidade & & te complexo, & crítico/reflexivo \\
\hline & & Ensinar & & faltou por & \\
\hline & & Cuidar & & parte de & \\
\hline & & Lixo & & alguns & \\
\hline & & Preservar & & discentes um & \\
\hline & & Desmatar & & $\begin{array}{l}\text { maior } \\
\text { desprendim } \\
\text { ento de } \\
\text { atenção com } \\
\text { a temática. }\end{array}$ & \\
\hline & Complexo & Processo & $69 \%$ & Surgiu um & Houve ampliação \\
\hline & Crítico & Sensibilizar & & entendi- & dos saberes \\
\hline & & $\begin{array}{l}\text { Promover } \\
\text { reflexões }\end{array}$ & & $\begin{array}{l}\text { mento dos } \\
\text { saberes }\end{array}$ & $\begin{array}{ll}\text { ambientais } & \text { dos } \\
\text { discentes e } & \text { das }\end{array}$ \\
\hline & & $\begin{array}{ll}\begin{array}{l}\text { Atitudes } \\
\text { mudanças }\end{array} & \text { de } \\
\end{array}$ & & $\begin{array}{l}\text { ambientais } \\
\text { de uma }\end{array}$ & $\begin{array}{ll}\text { dimensões } & \text { da } \\
\text { mesma através } & \text { do }\end{array}$ \\
\hline & & Conscientizar & & forma mais & curso aplicado e a \\
\hline & & Sobrevivência & & complexa, & visão do ser \\
\hline & & Cultura & & isso se deu & humano $\operatorname{com} a$ \\
\hline & & Corrente & & devido as & natureza começou \\
\hline & & Contribuir & & reflexões & a ser vista como \\
\hline & & Práticas & & $\begin{array}{l}\text { sobre todas } \\
\text { as }\end{array}$ & $\begin{array}{l}\text { uma relação que } \\
\text { necessita }\end{array}$ \\
\hline & & Sustentabilidade & & & necessita \\
\hline & & Valores & & perspectivas & \\
\hline & & Reeducar & & $\begin{array}{l}\text { que esse } \\
\text { saber se dá. }\end{array}$ & \\
\hline & & Equilíbrio & & saber se da, & \\
\hline & & População & & $\begin{array}{l}\text { os olnares } \\
\text { nassaram a }\end{array}$ & \\
\hline & & Social & & $\begin{array}{l}\text { pasarar uma } \\
\text { superar }\end{array}$ & \\
\hline & & Política & & visão apenas & \\
\hline & & Econômico & & ecológica. & \\
\hline & & Recursos & & & \\
\hline & & Essência & & & \\
\hline & & Influência & & & \\
\hline
\end{tabular}

Rev. Bras. Gest. Amb. Sustent., 2021, vol. 8, n. 19, p. 847-861. 
Tabela 2. Questão sobre desequilíbrio, preservação ambiental, consumo e qualidade de vida.

\begin{tabular}{|c|c|c|c|c|c|}
\hline Avaliação & $\begin{array}{l}\text { Unidades de } \\
\text { contextos }\end{array}$ & $\begin{array}{l}\begin{array}{l}\text { Unidade } \\
\text { registro }\end{array} \\
\end{array}$ & Frequência & Inferências & $\begin{array}{l}\text { Interpretações } \\
\text { prévias }\end{array}$ \\
\hline \multirow[t]{40}{*}{ Prévia } & \multirow[t]{20}{*}{ Reducionista } & Bens descartáveis & \multirow[t]{20}{*}{$56 \%$} & \multirow{40}{*}{$\begin{array}{l}\text { Na } \\
\text { atualidade as } \\
\text { discussões } \\
\text { ambientais } \\
\text { estão } \\
\text { tomando os } \\
\text { debates } \\
\text { educacionais, } \\
\text { consequente } \\
\text { mente, } \\
\text { levando as } \\
\text { pessoas a } \\
\text { adentrarem } \\
\text { melhor na } \\
\text { temática. A } \\
\text { sociedade } \\
\text { tem ficado } \\
\text { mais } \\
\text { antenada a } \\
\text { respeito da } \\
\text { preservação } \\
\text { ambiental e } \\
\text { da } \\
\text { globalização } \\
\text { e a própria } \\
\text { formação } \\
\text { profissional } \\
\text { técnica gera } \\
\text { busca de } \\
\text { conheciment } \\
\text { os voltados à } \\
\text { temática. }\end{array}$} & \multirow{40}{*}{$\begin{array}{lr}\text { Os debates } & \text { e } \\
\text { discussões } & \\
\text { apresentadas na } \\
\text { sociedade não } \\
\text { estão } \\
\text { críticas }\end{array}$} \\
\hline & & Compras & & & \\
\hline & & Poluição & & & \\
\hline & & Água & & & \\
\hline & & Saúde & & & \\
\hline & & Defasagem & & & \\
\hline & & Cuidado & & & \\
\hline & & Vigilância & & & \\
\hline & & Natureza & & & \\
\hline & & Desmatar & & & \\
\hline & & Área & & & \\
\hline & & Afetado & & & \\
\hline & & Irracionalidade & & & \\
\hline & & Desequilíbrio & & & \\
\hline & & Ambiente & & & \\
\hline & & Interferir & & & \\
\hline & & Conservado & & & \\
\hline & & Espécie & & & \\
\hline & & Não poluir & & & \\
\hline & & População & & & \\
\hline & \multirow{20}{*}{$\begin{array}{l}\text { Complexo } \\
\text { Crítico } \\
\text { Reflexivo }\end{array}$} & Conflito & \multirow[t]{20}{*}{$44 \%$} & & \\
\hline & & Socioeconômico & & & \\
\hline & & Produto & & & \\
\hline & & Ser humano & & & \\
\hline & & $\begin{array}{l}\text { Equilíbrio do } \\
\text { bem-estar social }\end{array}$ & & & \\
\hline & & Mundo capitalista & & & \\
\hline & & Consumismo & & & \\
\hline & & Sustentabilidade & & & \\
\hline & & Reutilização & & & \\
\hline & & Destruição & & & \\
\hline & & Degradação & & & \\
\hline & & Necessidade & & & \\
\hline & & Ação humana & & & \\
\hline & & Interações & & & \\
\hline & & Processo & & & \\
\hline & & Conhecimento & & & \\
\hline & & Prática & & & \\
\hline & & Envaidecer & & & \\
\hline & & Consciência & & & \\
\hline & & Sociedade & & & \\
\hline
\end{tabular}


Tabela 2. Continuação.

\begin{tabular}{|c|c|c|c|c|c|}
\hline Avaliação & $\begin{array}{l}\text { Unidade de } \\
\text { contexto }\end{array}$ & $\begin{array}{l}\text { Unidade de } \\
\text { registro }\end{array}$ & Frequência & Inferências & $\begin{array}{c}\text { Interpretações } \\
\text { prévias }\end{array}$ \\
\hline \multirow[t]{38}{*}{ Somatória } & \multirow[t]{12}{*}{ Reducionista } & Cuidado & \multirow[t]{12}{*}{$27 \%$} & \multirow{38}{*}{ 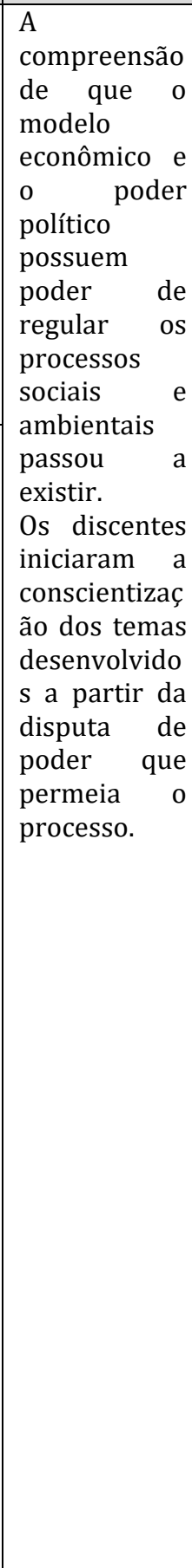 } & \multirow{38}{*}{$\begin{array}{l}\text { O curso de } \\
\text { extensão } \\
\text { provocou uma } \\
\text { ampliação do } \\
\text { pensamento } \\
\text { crítico/reflexivo } \\
\text { dos alunos, } \\
\text { fazendo com que } \\
\text { surgisse o } \\
\text { questionamento } \\
\text { acerca dos } \\
\text { conhecimentos } \\
\text { prévios das } \\
\text { temáticas a } \\
\text { apresentadas. } \\
\text { Foi estabelecida } \\
\text { uma visão mais } \\
\text { concretizada nos } \\
\text { discentes } \\
\text { respeito da } \\
\text { interferência dos } \\
\text { poderes sociais } \\
\text { nos processos de } \\
\text { conscientização e } \\
\text { informação } \\
\text { sobre as as } \\
\text { temáticas } \\
\text { ambientais. }\end{array}$} \\
\hline & & Comprar & & & \\
\hline & & Costumes & & & \\
\hline & & Produtos & & & \\
\hline & & Ambiente & & & \\
\hline & & $5 \mathrm{R}$ & & & \\
\hline & & Desmatamento & & & \\
\hline & & Afetação & & & \\
\hline & & Equilíbrio & & & \\
\hline & & Fauna e flora & & & \\
\hline & & População & & & \\
\hline & & Poluição & & & \\
\hline & \multirow{26}{*}{$\begin{array}{l}\text { Complexo } \\
\text { Crítico } \\
\text { Reflexivo }\end{array}$} & Efeito estufa & \multirow[t]{26}{*}{$73 \%$} & & \\
\hline & & Poder político & & & \\
\hline & & Consumo & & & \\
\hline & & Exploração & & & \\
\hline & & Estrutura social & & & \\
\hline & & $\begin{array}{l}\text { Estrutura } \\
\text { econômica } \\
\text { sustentável }\end{array}$ & & & \\
\hline & & Diversidade & & & \\
\hline & & Qualidade de vida & & & \\
\hline & & Recursos naturais & & & \\
\hline & & Ideal & & & \\
\hline & & Ação Humana & & & \\
\hline & & Orientação & & & \\
\hline & & Realidade atual & & & \\
\hline & & $\begin{array}{ll}\begin{array}{l}\text { Interferência } \\
\text { ciclo natural }\end{array} & \text { no } \\
\end{array}$ & & & \\
\hline & & Conscientizar & & & \\
\hline & & Reflorestamento & & & \\
\hline & & Destruição & & & \\
\hline & & $\begin{array}{l}\text { Manipulação da } \\
\text { conscientizacão }\end{array}$ & & & \\
\hline & & $\begin{array}{lll}\begin{array}{l}\text { Saúde } \\
\text { mental }\end{array} & & \text { e } \\
\end{array}$ & & & \\
\hline & & Agir na sociedade & & & \\
\hline & & $\begin{array}{l}\text { Interferência na } \\
\text { qualidade de vida }\end{array}$ & & & \\
\hline & & Riscos ambientais & & & \\
\hline & & Produtos; & & & \\
\hline & & Bem-estar & & & \\
\hline & & Social & & & \\
\hline & & $\begin{array}{l}\text { Modelo } \\
\text { econômico }\end{array}$ & & & \\
\hline
\end{tabular}

A Tabela 1 remete a compreensão de que os alunos inicialmente possuíam uma visão reducionista, quanto à educação ambiental e ao meio ambiente. De acordo com Leff (2006), a visão reducionista do meio ambiente se caracteriza pela falta de clareza sobre todas as dimensões que abrangem o meio ambiente, se restringindo a definição de natureza, como se os homens e as atividades humanas não fizesses tão parte do meio 
ambiente quanto à fauna e à flora, por exemplo. Tudo isso é muito bem evidenciado nas unidades de registros que relatam sobre educação ambiental e meio ambiente que são catalogadas com palavras que remetem fortemente a preservação da natureza.

A educação ambiental conscientiza sobre o mundo em que a sociedade está designada, para que a qualidade de vida possa ser melhor estabelecida sem um desequilíbrio do homem e o todo. Dessa maneira o maior objetivo da educação ambiental é buscar um equilíbrio em todos os modelos de comportamento do homem perante o meio, assim, detectamos que o mais provável é que haja uma falha no processo formativo de âmbito escolar, que foi fruto da formação dos discentes com uma lacuna referente aos saberes ambientais.

Leff (2007) aponta que a racionalidade ambiental se trata de um processo lento, pois, para tanto é necessária uma inversão do pensamento e da cultura já existente e a ressignificação dos conceitos com uma nova visão para com a educação ambiental e o meio ambiente.

Como observaremos no quadro a seguir os discentes chegam ao ensino médio/técnico com essa lacuna nos conhecimentos acerca da educação ambiental, a causa desta problemática possivelmente está relacionada à falta de abordagem dessa temática durante toda sua formação na educação básica.

Dessa forma, evidencia-se a necessidade de trabalho pedagógico que desenvolva a consciência crítica diante de toda a realidade que o meio ambiente e a educação ambiental estão inseridos, auxiliando os alunos a perceber a forma de inserção dos seres humanos, bem como estabelecendo níveis de interação e intervenção na natureza de forma saudável, não havendo a concepção de superioridade das pessoas sobre os outros elementos da natureza, pois fazemos parte de um mesmo lar, o planeta Terra.

As respostas referentes a essa questão sobre desequilíbrio, preservação ambiental, consumo e qualidade de vida, evidenciadas na Tabela 2, remetem concluir que um conjunto de ideias ou pensamentos de saberes ambientais são transmitidos de maneira ideológica na sociedade contemporânea, por meio dos meios de comunicação, educação, religião, afinal as respostas reducionistas em relação a avaliação prévia obtiveram estaticamente um valor próximo.

A ideologia, para Althusser (1977), é representação, mas acima de tudo são estruturas que impõem situações aos homens para que eles hajam sem a sua "consciência".

Mesmo que os debates tenham influenciado a ampliação de discussões sobre as problemáticas ambientais, os discentes ainda apresentam de acordo com suas respostas um nível insuficiente de criticidade sobre as causas de origem a crise ambiental remetida.

Existe um consumismo exagerado, que é embutido na atualidade, há o lucro exacerbado perante grandes empresas que auxiliam fortemente na intensidade da desigualdade social e na formação de opressão para com os menos favorecidos. Os educandos foram estimulados e submergiram em debates de caráter crítico e reflexivo. Compreenderam o desequilíbrio ambiental e foram levados a se conscientizar que o Estado age como forte centralizador de ações e limitador de ações. 0 homem é doutrinado para ser consumista e usufruir de forma exacerbada dos recursos naturais.

Não se pode pensar a natureza nem o ser humano sem a ação do ser humano na natureza. Existe uma identidade e relação interdependente entre os dois. Por um lado, ação humana na natureza é coletiva e se desenvolve pelo modo de vida de determinada época, por outro, as próprias transformações que o ser humano causa na natureza também são sofridas pelos mesmos.

Neste paradigma de consumo que traz desequilíbrio e má qualidade de vida, a educação no geral, e mais expressivamente a educação técnica de nível médio, que foi a qual fez parte deste estudo, deve reforçar suas funções de serviço para a sociedade e, mais especificamente, suas atividades voltadas para a erradicação da pobreza, da intolerância, 
da violência, do analfabetismo, da fome, da deterioração do meio ambiente e das doenças, principalmente mediante uma proposição interdisciplinar e transdisciplinar para analisar os problemas e as questões apresentadas.

Loureiro (2009) afirma que é um bom caminho minimizar a desigualdade social através de ações e políticas sociais que promovam bem-estar ambiental. A educação ambiental aparece como instrumento de democratização da consciência da sociedade e as questões sociais que estão inseridas nela.

Loureiro (2009) afirma ainda que é parte da história humana repensar as bases que regem o pensamento teórico, mas a implicação da mudança de racionalidade do consumo em larga escala estimulada a todo momento pelo capitalismo, desencadeou um contexto de crise ambiental, que o autor descrimina como raiz muito mais profundidade todo o problema.

Cristalizou-se no meio científico uma ideia errônea de uso apropriado dos recursos naturais. Torna-se fruto desse olhar desmedido sobre natureza e sociedade uma relação conflituosa que desqualifica especificidades culturais incólumes dos costumes ocidentais; ou seja, para ser qualificado como civilização é necessário estar enquadrado nas falácias inerentes ao processo eurocêntrico. Assim, são somadas as ações coletivas de degradação ambiental que passam a gerir no globo sobre a aura de um contexto desenvolvido, pela racionalidade do consumo exacerbado, gerando a chamada crise civilizatória.

Tabela 3. Questão sobre desenvolvimento e justiça ambiental.

\begin{tabular}{|c|c|c|c|c|c|}
\hline Avaliação & $\begin{array}{ll}\text { Unidade } \\
\text { contexto }\end{array}$ & $\begin{array}{l}\text { Unidade de } \\
\text { registro }\end{array}$ & Frequência & Inferências & $\begin{array}{l}\text { Interpretações } \\
\text { prévias }\end{array}$ \\
\hline \multirow[t]{17}{*}{ Prévia } & \multirow[t]{9}{*}{ Reducionista } & Tecnologia & \multirow[t]{9}{*}{$63 \%$} & \multirow{17}{*}{$\begin{array}{l}0 \\
\text { entendiment } \\
\text { o dos } \\
\text { discentes a } \\
\text { respeito de } \\
\text { justiça } \\
\text { ambiental } \\
\text { era o de que } \\
\text { era um } \\
\text { aspecto } \\
\text { totalmente } \\
\text { legal e o de } \\
\text { desenvolvim } \\
\text { ento como } \\
\text { um aspecto } \\
\text { totalmente } \\
\text { tecnológico. }\end{array}$} & \multirow{17}{*}{$\begin{array}{lr}\text { Os debates } \\
\text { educacionais } & \text { e } \\
\text { sociais } & \text { se } \\
\text { apresentam } & \text { de } \\
\text { forma ínfima } & \text { em } \\
\text { relação } & \text { ao } \\
\text { desenvolvimento } \\
\text { e r são } \\
\text { extremamente } \\
\text { ausentes rr ou } \\
\text { omissos no que } \\
\text { tange } & \text { às } \\
\text { discussões sobre } \\
\text { a justiça } & \text { ou } \\
\text { injustiça } & \\
\text { ambiental. } & \end{array}$} \\
\hline & & Conservação & & & \\
\hline & & Leis & & & \\
\hline & & Desmatamento & & & \\
\hline & & Punição & & & \\
\hline & & $\begin{array}{l}\text { Destruição } \\
\text { ambiental }\end{array}$ & & & \\
\hline & & Consumo & & & \\
\hline & & Recursos & & & \\
\hline & & $\begin{array}{l}\text { Humanos como } \\
\text { defensores do } \\
\text { meio ambiente }\end{array}$ & & & \\
\hline & \multirow{8}{*}{$\begin{array}{l}\text { Complexo } \\
\text { Crítico } \\
\text { Reflexivo }\end{array}$} & Sustentabilidade & \multirow[t]{8}{*}{$37 \%$} & & \\
\hline & & Consciência & & & \\
\hline & & Realidade & & & \\
\hline & & Meio social & & & \\
\hline & & Debate & & & \\
\hline & & $\begin{array}{l}\text { Impactos } \\
\text { ambientais }\end{array}$ & & & \\
\hline & & $\begin{array}{l}\text { Programas de } \\
\text { preservação } \\
\text { ambiental }\end{array}$ & & & \\
\hline & & Conscientização & & & \\
\hline
\end{tabular}


Tabela 3. Questão sobre desenvolvimento e justiça ambiental.

\begin{tabular}{|c|c|c|c|c|c|}
\hline Avaliação & $\begin{array}{l}\text { Unidade de } \\
\text { contexto }\end{array}$ & $\begin{array}{l}\text { Unidade } \\
\text { registro }\end{array}$ & Frequência & Inferências & $\begin{array}{l}\text { Interpretações } \\
\text { prévias }\end{array}$ \\
\hline \multirow[t]{22}{*}{ Somatória } & \multirow[t]{4}{*}{ Reducionista } & Injustiça & \multirow[t]{4}{*}{$25 \%$} & \multirow{22}{*}{$\begin{array}{l}\text { Acima de } \\
\text { tudo os } \\
\text { discentes } \\
\text { passaram a } \\
\text { compreende } \\
\text { r que a } \\
\text { injustiça } \\
\text { ambiental } \\
\text { está atrelada } \\
\text { a um } \\
\text { desenvolvim } \\
\text { ento } \\
\text { desigual } \\
\text { econômico. } \\
\text { Começaram } \\
\text { a entender } \\
\text { que nas } \\
\text { relações de } \\
\text { poderes há } \\
\text { dominação, } \\
\text { concentraçã } \\
\text { o de renda e } \\
\text { conflitos. }\end{array}$} & \multirow{22}{*}{$\begin{array}{lr}\text { Apesar } & \text { das } \\
\text { poucas } & \\
\text { discussões } & \\
\text { reflexivas } & \\
\text { desenvolvidas } \\
\text { na educação } \\
\text { básica, o curso } \\
\text { proporcionou a } \\
\text { criticidade e a } \\
\text { abertura r de } \\
\text { percepção das } \\
\text { relações r de } \\
\text { poder e sociais } \\
\text { existentes nos } \\
\text { discursos } \\
\text { desenvolvimenti } \\
\text { stas e r na } \\
\text { injustiça } \\
\text { ambiental } \\
\text { resultante deste } \\
\text { processo. }\end{array}$} \\
\hline & & Tecnologias & & & \\
\hline & & $\begin{array}{l}\text { Agredir o meio } \\
\text { ambiente }\end{array}$ & & & \\
\hline & & Evolução & & & \\
\hline & \multirow{18}{*}{$\begin{array}{l}\text { Complexo } \\
\text { Crítico } \\
\text { Reflexivo }\end{array}$} & $\begin{array}{l}\text { População } \\
\text { vulnerável }\end{array}$ & \multirow[t]{18}{*}{$75 \%$} & & \\
\hline & & Superpopulação & & & \\
\hline & & $\begin{array}{l}\text { Reestruturação } \\
\text { local }\end{array}$ & & & \\
\hline & & Sociedade & & & \\
\hline & & Desenvolvimento & & & \\
\hline & & Luta & & & \\
\hline & & Habitat & & & \\
\hline & & $\begin{array}{l}\text { Desenvolvimento } \\
\text { econômico }\end{array}$ & & & \\
\hline & & $\begin{array}{l}\text { antagônico à } \\
\text { justiça ambiental }\end{array}$ & & & \\
\hline & & $\begin{array}{l}\text { Concentração de } \\
\text { renda }\end{array}$ & & & \\
\hline & & Sustentável & & & \\
\hline & & Conflitos & & & \\
\hline & & $\begin{array}{l}\text { Direitos } \\
\text { ambientais }\end{array}$ & & & \\
\hline & & $\begin{array}{l}\text { Recursos } \\
\text { renováveis }\end{array}$ & & & \\
\hline & & $\begin{array}{l}\text { Impactos sociais e } \\
\text { ambientais }\end{array}$ & & & \\
\hline & & $\begin{array}{l}\text { Degradação } \\
\text { ambiental }\end{array}$ & & & \\
\hline & & Dominação & & & \\
\hline & & $\begin{array}{l}\text { Desenvolvimento } \\
\text { econômico social e } \\
\text { cultural }\end{array}$ & & & \\
\hline
\end{tabular}

A partir dos dados supracitados, que tem por base a terceira pergunta do questionário sobre desenvolvimento e justiça ambiental, expostas na Tabela 3, percebe-se que os discentes possuíam uma visão de que justiça ambiental seria a definição de algo de perspectiva legal, ou seja, sem a compreensão de que a tomada de poder por uma pequena parte da população está atrelada a um desequilíbrio e a jogada de impactos pelo uso de recursos naturais em maior proporção na polução mais pobre.

Leff (2007) propõe a epistemologia ambiental, na qual discute uma nova racionalidade sobre o pensamento do meio ambiente. Para alcançar a epistemologia ambiental, toda a racionalidade de construção sobre conhecimento deve ser reorganizada em prol de minimizar as fissuras causadas pelo sistema capitalista, no qual, desde a época da Revolução Industrial se volta para uma razão de apropriação dos recursos naturais sem a devida preocupação com os elementos ao seu redor.

A proposta epistemológica inverte toda a cadeia da racionalidade científica pautada ainda em fins do pensamento liberal para partirem do pressuposto do homem, da sociedade, da natureza, dos recursos ambientais e das culturas como produtoras de um conhecimento unificado em suas particularidades. 
Leff (2007) aponta ainda para a dicotomia entre racionalidade capitalista e racionalidade ambiental. Destacando a racionalidade capitalista baseada no predomínio dos processos tecnológicos desconhecendo os potenciais ecológicos e gerando desequilíbrio ambiental, concentração de poder, centralização econômica e extrema divisão de trabalho. Enquanto a racionalidade ambiental pauta-se o desenvolvimento das forças produtivas que incorpore as condições ecológicas de produção, os valores culturais e as motivações sociais.

Para essa racionalidade ambiental, Leff (2007) sugere a interdisciplinaridade como uma seleção de variáveis e dimensões significativas, diversas e plural, para apreender a problemática ambiental e fundamentar a gestão ambiental. Esses conhecimentos surgem da exigência dos diversos campos do saber e científico que visa encontrar soluções para a crise ambiental, propondo novos enfoques metodológicos.

Dessa forma, a produção e aplicação desses conhecimentos produziriam uma certa autonomia cultural, pela autogestão tecnológica dos recursos das comunidades, pela propriedade das terras e por uma apropriação igualitária dos recursos naturais.

Para isso, a sustentabilidade depende do enfrentamento simultâneo dos problemas ambientais derivados da pobreza e da riqueza. Assim, é necessária uma prática educativa que vincule a relação humana com a natureza, que pleiteie uma mudança de comportamentos e atitudes ecologicamente corretos.

Considerar a mudança social a partir da educação ambiental é assumir o compromisso por uma educação com responsabilidade social, empenhada também na transformação social. Implica uma reelaboração conceitual, mas também assumir outras posturas decorrentes da incorporação da perspectiva da questão ambiental como uma questão de justiça distributiva, para uma coerente tradução nas estratégias de ação das práticas pedagógicas.

\section{Conclusões}

A educação ambiental em si é um agente transformador social, os problemas ambientais causados pela globalização se inter-relacionam, ou seja, em hipótese alguma podem ser considerados fatores isolados de cada realidade existente. Dessa maneira, o modelo individualista e concentrador de riquezas que se definiu o convívio na sociedade, gera grandes destruições e apenas um transformador de caráter mais profundo pode conscientizar as pessoas sobre as reais vivências.

0 estudo aponta para a presença de uma educação ambiental nos ambientes escolares, que não tem abarcado a complexidade que a temática representa. Diante dos fatores apresentados nesta pesquisa podemos afirmar que, os saberes ambientais devem estar bem distantes das percepções reducionistas, nos quais são levados em consideração apenas a necessidade da preservação ambiental.

Consideramos que o projeto de extensão "Meio Ambiente e Ação Humana: uma ação educativo-ambiental na Escola Técnica de Saúde da UFPB", com o curso intitulado "Meio Ambiente e Ação Humana: uma perspectiva educacional na formação do técnico", obteve êxito em promover a conscientização de agentes transformadores de suas próprias realidades através de uma formação extracurricular para os discentes dos cursos técnicos de nível médio da Escola Técnica de Saúde da UFPB.

Os discentes obtiveram, através das aulas, visões mais críticas e reflexivas acerca de todo o contexto da ação humana para com o meio ambiente, em seus diversos aspectos. Em uma relação simbiótica, esses alunos serão agentes multiplicadores de conscientização sobre meio ambiente em seus mais diversos locais de convívio, inclusive o empregatício.

Esta pesquisa torna-se, portanto, uma crítica ao sistema de ensino brasileiro como um todo, bem como a sugestão de reestruturação dos cursos de formação de professores, que pouco abordam a educação ambiental em seu ementário. 


\section{Conflito de interesses}

Os autores declaram não haver conflito de interesses.

\section{Referências}

Althusser, L. Ideologia e aparelhos ideológicos do estado. Lisboa: Editorial Presença, 1977.

Bardin, L. Análise de conteúdo. São Paulo: Edições 70, 2011.

Brasil. Lei no 6.938, de 31 de agosto de 1981. Dispõe sobre a Política Nacional do Meio Ambiente, seus fins e mecanismos de formulação e aplicação, e dá outras providências. Disponível em: <http://www.planalto.gov.br/ccivil_03/Leis/L6938.htm>. Acesso em: 03 nov. 2019.

Brasil. Resolução MEC/CNE/CEB no 06, de 20 de setembro de 2012. Define as Diretrizes Curriculares Nacionais para a Educação Profissional Técnica de Nível Médio. Disponível em: <https://www.gov.br/mec/pt-br/media/seb-1/pdf/leis/resolucoes_cne/ rceb006_12.pdf>. Acesso em: 10 nov. 2019.

Brasil. Resolução MEC/CNE/CP no 2, de 15 de junho de 2012. Estabelece as Diretrizes Curriculares Nacionais para a Educação Ambiental. Disponível em: <http://portal.mec.gov.br/index.php?option=com_docman\&view=download\&alias=10988 -rcp002-12-pdf\&category_slug=maio-2012-pdf\&Itemid=30192 >. Acesso em: 10 nov. 2019.

Camozzato, M. M. A importância individual do integrante da sociedade em rede na proteção do meio ambiente. Revista Eletrônica do Curso de Direito da UFSM, v. 8, p. 60-69, 2012. https://doi.org/10.5902/198136948218

Freire, P. Pedagogia do oprimido. 42. ed. Rio de Janeiro: Paz e Terra, 1996.

Godoy, A. S. Introdução à pesquisa qualitativa e suas possibilidades. Revista de Administração de Empresas, v. 35, n. 2, p. 57-63, 1995.

Grossi, Y. S. Mina de Morro Velho: a extração do homem, uma história de experiência operária. São Paulo: Paz e Terra, 1981.

Hobsbawm, E. A era das revoluções 1789-1848. Rio de Janeiro: Paz e Terra, 2014.

Leff, E. Epistemologia ambiental. 4. ed. rev. São Paulo: Cortez, 2007.

Loureiro, C. F. B. Educação ambiental com compromisso social: o desafio da superação das desigualdades. In: Castro, R.; Layarargues, P.; Loureiro, C. (Orgs.). Repensar a educação ambiental: um olhar crítico. São Paulo: Cortez, 2009.

Loureiro, C. F. B. Educação ambiental e movimentos sociais na construção da cidadania ecológica e planetária. In: Loureiro, C. F. B.; Layrargues, P. P.; Castro, R. S. (Orgs.). Educação ambiental: repensando o espaço da cidadania. 4. ed. São Paulo: Cortez, 2008.

Thiollent, M. Metodologia da pesquisa-ação. 18. ed. São Paulo: Cortez, 2011.

Informação da Licença: Este é um artigo Open Access distribuído sob os termos da Licença Creative Commons Attribution, que permite uso irrestrito, distribuição e reprodução em qualquer meio, desde que a obra original seja devidamente citada. 